\title{
Natural and Experimental Evidence Drives Marmosets for Research on Psychiatric Disorders Related to Stress
}

OPEN ACCESS

Edited by:

Rafael S. Maior

University of Brasilia, Brazil

Reviewed by:

Luiz E. Mello,

Federal University of São Paulo, Brazil Susanne Nikolaus, Heinrich Heine University of

Düsseldorf, Germany

*Correspondence:

Maria Bernardete Cordeiro de Sousa mbcsousa@neuro.ufrn.br

Specialty section: This article was submitted to Pathological Conditions, a section of the journal Frontiers in Behavioral Neuroscience

Received: 01 March 2021 Accepted: 07 May 2021

Published: 11 June 2021

Citation:

de Sousa MBC, de Meiroz Grilo MLP and Galvão-Coelho NL (2021) Natural and Experimental Evidence Drives Marmosets for Research on Psychiatric Disorders Related to Stress. Front. Behav. Neurosci. 15:674256. doi: 10.3389/fnbeh.2021.674256

\author{
Maria Bernardete Cordeiro de Sousa ${ }^{1,2,3,4 *}$, Maria Lara Porpino de Meiroz Grilo ${ }^{2,4}$ and \\ Nicole Leite Galvão-Coelho ${ }^{2,4,5,6}$
}

${ }^{1}$ Brain Institute, Federal University of Rio Grande do Norte (UFRN), Natal, Brazil, ${ }^{2}$ Postgraduation Program in Psychobiology, Federal University of Rio Grande do Norte (UFRN), Natal, Brazil, ${ }^{3}$ Postgraduation Program in Neuroscience, Federal University of Rio Grande do Norte (UFRN), Natal, Brazil, ${ }^{4}$ Laboratory of Advanced Studies in Primates, UFRN-Brazil, and Laboratory of Hormone Measurement, Department of Physiology and Behavior, Natal, Brazil, ${ }^{5}$ Department of Physiology and Behavior, Federal University of Rio Grande do Norte (UFRN), Natal, Brazil, ${ }^{6}$ National Institute of Science and Technology in Translational Medicine, Ribeirao Preto, Brazil

Knowledge of the behavioral ecology of marmosets carried out in their natural habitat associated with the advent of a non-invasive technique for measuring steroid hormones in feces has made a significant contribution to understanding their social relationships and sexual strategies. These studies showed that they are mainly monogamous, live in relatively stable social groups according to a social hierarchy in which females compete and males cooperate, and form social bonds similar to humans, which makes this species a potential animal model to study disorders related to social stress. In addition, laboratory studies observed the expression of behaviors similar to those in nature and deepened the descriptions of their social and reproductive strategies. They also characterized their responses to the challenge using behavioral, cognitive, physiological, and genetic approaches that were sexually dimorphic and influenced by age and social context. These findings, added to some advantages which indicate good adaptation to captivity and the benefits of the birth of twins, small size, and life cycle in comparison to primates of the Old World, led to their use as animal models for validating psychiatric diseases such as major depression. Juvenile marmosets have recently been used to develop a depression model and to test a psychedelic brew called Ayahuasca from the Amazon rainforest as an alternative treatment for major depression, for which positive results have been found which encourage further studies in adolescents. Therefore, we will review the experimental evidence obtained so far and discuss the extension of the marmoset as an animal model for depression.

Keywords: New World primates, behavior, HPA axis, animal model, depression 


\section{INTRODUCTION}

Several species and numerous protocols have been tested to validate translational animal models which better mimic the physiological and behavioral states observed in human psychopathologies associated with chronic social stress including fish species (Øverli et al., 2004; Schjolden et al., 2005), birds (Roberts et al., 2007), rodents (Sgoifo et al., 1999; Veenema et al., 2003; Kompagne et al., 2008; Martinez et al., 2008; Hennessy et al., 2009), sheep (Stackpole et al., 2006), pigs (van der Staay et al., 2008), and non-human primates (Barros and Tomaz, 2002; Dettling et al., 2007).

These models show mammals present great genetic similarities and share corresponding neurophysiological mechanisms involved in socialization. However, their social organizations reveal a large range of differences in their size, composition, social bonding, parental care, and reproductive skew, creating a diversity of societies which is currently under investigation in terms of studying their complexity. This evidence demonstrates that the evolutionary pressures related to the natural environment demand adaptive responses which lead to a great diversity of strategies, thus making it difficult to apply the findings of some animal models to people. Therefore, these interspecific differences limit the suitability of a given species as an experimental model for comparative studies with humans (Kappeler, 2019), including non-human primates.

The common marmoset is a small New World primate and has gained attention mainly due to its complex social organization. This species has several social behaviors which are linked to auditory and visual cues like humans, including that they show gazing behavior, intentional pro-social behavior (Burkart and van Schaik, 2020; also known as altruism in humans), and observational social learning. In fact, their social cognition and communication seem more similar to that of humans than those of rhesus monkeys (Burkart and Finkenwirth, 2015). It is also suggested that humans and marmosets share main traits as cooperative breeders such as social tolerance and social monitoring resulting from cooperative breeding (Burkart and Finkenwirth, 2015).

Marmosets exhibit a range of changes at physiological and behavioral levels when facing stressful situations which depends on the individual, social and environmental characteristics resembling those observed in humans. They also have a well-defined ethogram (Stevenson and Poole, 1976), and there are procedures to measure cortisol in blood and urine, a non-invasive technique using feces (see de Sousa, 2017), and new methods have more recently been standardized for saliva (Cross and Rogers, 2004; Cross et al., 2004; Ash et al., 2018) in the laboratory and in hair in captive (Phillips et al., 2018) and wild marmosets at different ages (Garber et al., 2020).

These features make this species relevant for their use as a model in psychiatry studies related to chronic stress. It is largely understood that chronic social stress is the main etiology of Major Depressive Disorder (MDD; Tafet and Bernardini, 2003), General Anxiety Disorder (GAD; Juruena et al., 2020), and Post-Traumatic Stress Disorder (PTSD; Yehuda et al., 2015).
In this sense, the cortisol profile is considered the marker of hypothalamus-pituitary-adrenal (HPA) axis disruption and has been used as a potential biomarker of some psychiatric syndromes (Dieleman et al., 2015; Herman et al., 2016). Thus, in this minireview, we aim to analyze recent studies to provide more evidence for the use of common marmosets as one of the strongest candidates today as an experimental model for research on psychiatric disorders related to stress.

\section{BEHAVIORAL AND HYPOTHALAMIC- PITUITARY-ADRENAL AXIS CHARACTERIZATION IN COMMON MARMOSETS}

Despite there being several protocols for inducing psychiatric disorders in animal models such as genetic (Sasaki, 2015), pharmacological (Costall et al., 2011; Pryce et al., 2011; Yasue et al., 2015), and behavioral (Cilia and Piper, 1997; Barros et al., 2000, 2008; Dettling et al., 2002b), the etiological models for mental disorders associated to chronic stress based on social challenging are closer to that which triggers human PTSD (Dettling et al., 2002a,b, 2007), GAD (Cilia and Piper, 1997; Barros et al., 2000, 2008) and MDD (Johnson et al., 1996; Galvão-Coelho et al., 2008, 2017). Therefore, animal models are promising to gain larger emphasis in scientific studies. In order to do so, it is essential to investigate and understand the neurobiological mechanisms underlying the associated physiological and psychological mechanisms that support the analysis of psychiatric disorders. The data obtained in studies using non-human models have significant limitations because the etiology of psychiatric disorders is characterized by a multiplicity of causal factors and symptoms (Salgado and Sandner, 2013). Furthermore, in the perspective that it is the combination of "nature" and "nurture" which contribute to different phenotypes of susceptibility and resilience to developing mood disorders (Hollander et al., 2020), the need for substantial information to attain the validation criteria of an animal model is strengthened.

The systematic study of the behavior and development of common marmosets (Callithrix jacchus) living in captivity in colonies worldwide started in the 1970s (Epple, 1970; Abbott and Hearn, 1978), and wild groups started to be monitored in Brazil in the 1980s (Stevenson and Rylands, 1988). In this context, the common marmoset is currently one of the most studied species among non-human primates in both wild and in captivity situations and consequently, the marmoset emerges as a distinct experimental model with respect to the amount of information available in both settings.

\section{Natural Environmental Studies}

Common marmosets are small New World primates of the Callitrichidae family. This species is not threatened and easily found in Brazilian Atlantic Forest, usually living in stable social groups composed from three to 19 familiar individuals (Stevenson and Rylands, 1988; Digby, 1995; Schiel and Souto, 2017). The group composition varies depending 
on the number of births, migrations, and disappearances (Digby and Barreto, 1993). Studies also show that they are cooperative breeders, suggesting extended family groups in which reproductive pairs (dominants) develop special social bonds, present parental and alloparental care more frequently involving older siblings and close relatives (Digby, 1995). Despite groups generally being composed of relatives, unrelated members have also been identified in the social group (Faulkes et al., 2009).

The core of the social group is the monogamous breeding couple, which has very low sexual body dimorphism, but polygynous groups have also been described (Digby, 1999; Arruda et al., 2005). It is interesting to note that marmoset males are more cooperative and build stronger intra-sexual ties, while female marmosets exhibit higher intra-sexual competition levels (Arruda et al., 2005; Yamamoto et al., 2010; de Sousa et al., 2019).

The intra-group organization of marmosets can be disturbed during social reproduction dynamics, as shown in situations where dominant females perpetrated infanticide toward the offspring of subordinates (Digby, 1995; Arruda et al., 2005) or during the subordinate scaping of ovulatory inhibition (Albuquerque et al., 2001), as well as when males were facing territorial dispute challenges (Digby, 1995; LazaroPerea, 2001), thus producing tensions and activating the stress response system (de Sousa et al., 2019). Furthermore, both behavioral repertoire (episodes of aggression and open fights expressed by piloerection displays, scent marking, and anogenital presentation) and associated endocrine correlates increased cortisol in females and cortisol and androgens in males during these situations, being characteristic of the stress response of the animals when exposed to natural stressors. These reactions characterize the typical stress response that is shared by mammals, including humans.

\section{Laboratory Studies}

The first studies developed in common marmosets under captive conditions date from the 1970s throughout the 1980s and described data related to marmosets' behavior living in colonies, such as: living in family groups (Epple, 1970), breeding and development (Abbott and Hearn, 1978; Tardif et al., 2003), parental care (Ingram, 1977), first cohabitation weeks of common marmoset heterosexual pairs (Evans and Poole, 1983; Woodcock, 1983), and the construction of an ethogram of social behavior in different contexts (piloerection displays, adult play, copulatory, aggressive, and prey-catching behavior and vocalization; Stevenson and Poole, 1976). These studies were fundamental to provide information to researchers to learn about and better understand the role of their behaviors and how they vary along with their age, as well as the endocrine profile in the transition phases of puberty (Abbott and Hearn, 1978), first ovulation and initial age for pregnancy (Tardif et al., 2003). Three classifications were proposed to characterize the development stages of the common marmoset (Missler et al., 1992; Yamamoto, 1993; de Castro Leão et al., 2009), and a comparative analysis was carried out (Schultz-Darken et al., 2016) providing a reference scale for long-term studies.
A longitudinal study by our laboratory on the developmental stages of common marmosets from the infant stage (3 months) to the sub-adult (15 months) describes the cortisol variation in males and females in relation to age and sex. Cortisol changes throughout the marmoset's life stages were recorded, with the highest cortisol levels being observed in the infant phase and tending to decrease with development, especially in males (de Sousa et al., 2015). A better understanding of marmoset development allows appropriate parameters to be available to compare the normal and abnormal development after birth and to assist in psychiatric studies of early life chronic stress (Dettling et al., 2002a,b, 2007; Pryce et al., 2004a,b, 2011; Arabadzisz et al., 2010) and to assess neurodevelopment from the perspective of using biomedical research in transgenic approaches (Sasaki et al., 2009).

Sexual dimorphism is observed from the juvenile stage at baseline cortisol levels in favor of female marmosets, which have higher fecal cortisol levels than males (de Sousa et al., 2015). However, despite the sex, it is suggested that the marmoset's temperament also modulates basal cortisol levels, with three distinct basal cortisol profiles being described in adult marmosets of both sexes scaled as low, medium, and high (Galvão-Coelho et al., 2008).

Moreover, a sexual dimorphic stress response was evidenced by distinct cortisol increases when adult marmosets were moved to new cages, which varies depending on the type of stressor, the presence or not of a co-specific, and the type of social support (Galvão-Coelho et al., 2012; de Menezes Galvão et al., 2016). Dyad formation also triggered a sexual dimorphic stress response in adult marmosets. Females were more reactive than males when facing a pair formation as well as in response to isosexual dyad formation, independent of the co-specific being familiar or not (Galvão-Coelho et al., 2012). Adult male marmosets were also more sensitive to social isolation, showing larger cortisol increases (Castro and de Sousa, 2005).

Other convergent data in terms of sexual dimorphism in the stress response in marmosets was evidenced in a genetic study where the NTRK2, CREB1, and CRTC1 genes possibly associated with CREB1-BDNF-NTRK2 pathway have a higher expression level in females, suggesting greater demand for this signaling cascade in females (Nogueira et al., 2018). This pathway presents an important role in brain adaptation to stress and variations in these genes have been identified as probable risk factors for depression in humans (Juhasz et al., 2011).

Stress and psychiatric studies are usually based on male models. However, there is a long-standing demand for psychiatric models which include both sexes (Kokras and Dalla, 2014; Alshammari, 2021). Therefore, sexual dimorphism in the HPA axis and in the autonomic component of the stress response in marmosets are important characteristics of this species which resemble humans and enables its use in sex-related psychopathology studies. It is assumed that better treatments can be validated if both sexes are included as pre-clinical models of psychiatric diseases (Dalla et al., 2010).

Laboratory studies also demonstrated a diurnal (de Sousa and Ziegler, 1998; Ferreira Raminelli et al., 2001) and 
annual fluctuation in plasma cortisol in common marmosets over a 2-year interval in which a marginal effect of sex was observed with females showing higher levels during dry seasons (Cunha et al., 2007). The annual variation in cortisol was associated with precipitation and temperature, but not with the photoperiod, due to the small variation in the photophase length at the Equator line where our animals live. Therefore, the circadian and seasonal change in cortisol can also contribute to approaches which explore some characteristics in physiological regulation using appropriate protocols which may be relevant for models to investigate circadian changes in the cortisol profile of depressed patients (Keller et al., 2006) and for seasonal depression (Thalén et al., 1997).

\section{THE COMMON MARMOSET AS AN ANIMAL MODEL TO STUDY PSYCHOPATHOLOGIES ASSOCIATED WITH CHRONIC STRESS}

Despite recognition of increasing psychiatric disorder incidences being related to chronic stress in adolescents and the importance of chronic stress in this ontogenetic phase on long-term non-adaptive neuroplasticity changes (Thapar et al., 2012; Knowles et al., 2021), a large part of the literature about chronic stress related to neuropsychiatric disorders using marmoset models have only explored adult (Johnson et al., 1996; Cilia and Piper, 1997; Barros et al., 2000, 2008) and infant (Dettling et al., 2002a,b, 2007) ages. Therefore, being aware of this gap, our group recently validated the marmoset as a juvenile animal model for major depression (Galvão-Coelho et al., 2017).

In aiming at the complete validation of this juvenile marmoset animal model for major depression, we developed a protocol addressing: (a) ecological validity, which means that the symptoms in this model were triggered by similar occurrences for human diseases, and in this case we used the social isolation protocol; (b) construct validity: animals showed activation of physiological processes in a similar way to humans, such as cortisol levels; (c) face validity: the animals expressed symptoms/behavior changes similar to those of humans, such as changes in appetite and anhedonia; (d) predictive validity: animals and humans showed similar responses to treatments; (e) interrelational validity: we investigated the model in several domains such as behaviors, molecular biomarkers and cognition; (f) evolutionary criteria: reflects the ability of the proposed model to investigate specific domains in various species such as anhedonia, body weight and cortisol analysis, which can be done on marmosets, humans and other species such as rodents; and (g) population validity: the capacity of the proposed model to reflect the natural variance of phenotypes observed in the general population, as observed in some studies in the literature (GalvãoCoelho et al., 2008, 2017).

In this context, male and female juvenile marmosets (approximately 7 months) were subjected to a chronic social stressor protocol (13 weeks of social isolation) to induce a state of depression. Next, fecal cortisol, body weight, and some intra and interspecific behaviors were analyzed in the stressed group and compared with a control group where marmosets continued to live with the family throughout the study. In short, we observed a behavioral and neuroendocrine depressive state similar to patients with depression (Dean and Keshavan, 2017; Santiago et al., 2020) and other non-human primate models of depression (Li et al., 2013; Hennessy et al., 2014) for both sexes isolated from marmosets (male; female), but not for animals kept with the family. Symptoms included a significant reduction in cortisol levels, an increase in anxiety-like behavior (stereotypes, such as scratching and body piloerection), presence of anhedonia, sexual dimorphic changes in diet and body weight (Galvão-Coelho et al., 2017). Most of the altered behaviors, such as scratching, as well as the change in cortisol levels, were reversed by treatment with nortriptyline (7 days), but not by the vehicle (Galvão-Coelho et al., 2017).

The validation of this protocol gave way to developing depressive juvenile models with other non-human primate species (Teng et al., 2021) and enabled a step forward when a potential new alternative drug therapy (nortriptyline) for depression was tested (da Silva et al., 2019). Using that same validated protocol, some male and female juvenile marmosets (male; female) were treated with a single dose of ayahuasca (da Silva et al., 2019). Ayahuasca is a psychedelic decoction made from combining two plants from the Amazon rainforest: Psychotria viridis and Banisteriopsis caapi, which has shown promising fast antidepressant effects in humans (Palhano-Fontes et al., 2014, 2021; Perkins et al., 2021; Sarris et al., 2021). Thus, we observed a fast recovery in the decreased cortisol levels (hypocortisolemic state) and the bodyweight of depressive-like marmosets to the baseline values $24 \mathrm{~h}$ after an acute dose of Ayahuasca, and not after the vehicle, as well as reductions in anxiety-like stereotypic behaviors. Additionally, the single dose of ayahuasca also had long-lasting effects (14 days) and seemed to be more promising than nortriptyline treatment (da Silva et al., 2019).

These findings in the marmoset supported the development of clinical trials using ayahuasca treatment for resistant depression and showed positive results, including some similar to those seen in the marmoset (for example, regulating cortisol levels; de Almeida et al., 2019; Palhano-Fontes et al., 2019; Galvão-Coelho et al., 2020, 2021).

\section{FUTURE DIRECTIONS}

As mentioned earlier in this review, some scientists argue that current animal models are insufficient to express the full extent of mood disorders and therefore have no real value in understanding mental illness. However, new research initiatives to integrate the effort to study mental disorders, such as the Roadmap for Mental Health Research in Europe (ROAMER; Haro et al., 2014) and Research Domain Criteria (RDoC), funded by European and American public and private institutions (Insel et al., 2010; Elfeddali et al., 2014) intend to build a matrix of variables which constitute a unit of analysis involving studies from genetic, physiological, behavioral, and self-report evaluations. New information is added or contributions are 
made in these projects by revision of earlier knowledge on psychopathology analysis of symptoms, and both initiatives will facilitate progress in this field. They argue that these disorders are too complex to try to understand globally, so the knowledge gained step-by-step should provide more clarity and effectiveness. In addition, some specific symptoms are common to different psychopathologies, so that understanding one symptom for a certain disorder can be applied to another. Therefore, this new understanding makes studies on animal models even more important, since it is easier to focus on fewer symptoms and their pathophysiological correlates and their management. In turn, encouraging the development of new protocols and stimulating new studies on biomarkers, as well as on the development of new drugs. In addition, marmosets are the focus of a large-scale Japanese project called Brain Mapping by Integrated Neurotechnologies for Disease Studies (Brain/MINDS; Okano and Mitra, 2015; Okano et al., 2015), and new colonies of marmosets show that the use of this small neotropical primate as experimental models continues to

\section{REFERENCES}

Abbott, D. H., and Hearn, J. P. (1978). Physical, hormonal and behavioural aspects of sexual development in the marmoset monkey, Callithrix jacchus. Reproduction 53, 155-166. doi: 10.1530/jrf.0.0530155

Albuquerque, A. C. S. R., de Sousa, M. B. C., Santos, H. M., and Ziegler, T. E. (2001). Behavioral and hormonal analysis of social relationships between oldest females in a wild monogamous group of common marmosets (Callithrix jacchus). Int. J. Primatol. 22, 631-645. doi: 10.1023/A:1010741702831

Alshammari, T. K. (2021). Sexual dimorphism in pre-clinical studies of depression. Prog. Neuropsychopharmacol. Biol. Psychiatry 105:110120. doi: 10.1016/j. pnpbp.2020.110120

Arabadzisz, D., Diaz-Heijtz, R., Knuesel, I., Weber, E., Pilloud, S., Dettling, A. C., et al. (2010). Primate early life stress leads to long-term mild hippocampal decreases in corticosteroid receptor expression. Biol. Psychiatry 67, 1106-1109. doi: 10.1016/j.biopsych.2009.12.016

Arruda, M. F., Araújo, A., de Sousa, M. B. C., Albuquerque, F. S., Albuquerque, A. C. S. R., and Yamamoto, M. E. (2005). Two breeding females within free-living groups may not always indicate polygyny: alternative subordinate female strategies in common marmosets (Callithrix jacchus). Folia Primatol. 76, 10-20. doi: 10.1159/000082451

Ash, H., Smith, T. E., Knight, S., and Buchanan-Smith, H. M. (2018). Measuring physiological stress in the common marmoset (Callithrix jacchus): validation of a salivary cortisol collection and assay technique. Physiol. Behav. 185, 14-22. doi: 10.1016/j.physbeh.2017.12.018

Barros, M., Boere, V., Huston, J. P., and Tomaz, C. (2000). Measuring fear and anxiety in the marmoset (Callithrix penicillata) with a novel predator confrontation model: effects of diazepam. Behav. Brain Res. 108, 205-211. doi: 10.1016/s0166-4328(99)00153-9

Barros, M., Maior, R. S., Huston, J. P., and Tomaz, C. (2008). Predatory stress as an experimental strategy to measure fear and anxiety-related behaviors in non-human primates. Rev. Neurosci. 19, 157-169. doi: 10.1515/revneuro.2008. 19.2-3.157

Barros, M., and Tomaz, C. (2002). Non-human primate models for investigating fear and anxiety. Neurosci. Biobehav. Rev. 26, 187-201. doi: 10.1016/s01497634(01)00064-1

Burkart, J. M., and Finkenwirth, C. (2015). Marmosets as model species in neuroscience and evolutionary anthropology. Neurosci. Res. 93, 8-19. doi: 10.1016/j.neures.2014.09.003

Burkart, J. M., and van Schaik, C. P. (2020). Marmoset prosociality is intentional. Anim. Cogn. 23, 581-594. doi: 10.1007/s10071-020-01363-6

Castro, D. C., and de Sousa, M. B. C. (2005). Fecal androgen levels in common marmoset (Callithrix jacchus) males living in captive family present a promising future for scientific research, including for investigations of neuropsychiatric diseases.

\section{AUTHOR CONTRIBUTIONS}

MS and NG-C wrote and edited the manuscript. MS, NG-C, and MM performed bibliographic research and main drafting. All authors contributed to the article and approved the submitted version.

\section{FUNDING}

This work was supported by the Brazilian Council for Scientific and Technological Development (CNPq) Proc. No. 306051/2017-6 to MS and scholarship from Coordination for the Improvement of Higher Education Personnel (CAPES) Proc. No. 88887.357778/2019-00 to MM. This study was financed in part by the Coordenação de Aperfeiçoamento de Pessoal de Nível Superior - Brasil (CAPES) - Finance Code 001.

groups. Braz. J. Med. Biol. Res. 38, 65-72. doi: 10.1590/s0100-879x2005000 100011

Cilia, J., and Piper, D. (1997). Marmoset conspecific confrontation: an ethologically-based model of anxiety. Pharmacol. Biochem. Behav. 58, 85-91. doi: 10.1016/s0091-3057(96)00376-0

Costall, B., Domeney, A. M., Gerrard, P. A., Kelly, M. E., and Naylor, R. J. (2011). Zacopride: anxiolytic profile in rodent and primate models of anxiety. J. Pharm. Pharmacol. 40, 302-305. doi: 10.1111/j.2042-7158.1988.tb05254.x

Cross, N., Pines, M. K., and Rogers, L. J. (2004). Saliva sampling to assess cortisol levels in unrestrained common marmosets and the effect of behavioral stress. Am. J. Primatol. 62, 107-114. doi: 10.1002/ajp.20005

Cross, N., and Rogers, L. J. (2004). Diurnal cycle in salivary cortisol levels in common marmosets. Dev. Psychobiol. 45, 134-139. doi: 10.1002/dev.20023

Cunha, M. S., Fernandes, L. C., Vivacqua, C. A., and de Sousa, M. B. C. (2007). Annual variation in plasma cortisol levels in common marmosets, Callithrix jacchus. Biol. Rhythm Res. 38, 373-381. doi: 10.1080/0929101060 1030669

da Silva, F. S., Silva, E. A. S., de Sousa, G. M. Jr., Maia-de-Oliveira, J. P., SoaresRachetti, V. D. P., de Araujo, D. B., et al. (2019). Acute effects of ayahuasca in a juvenile non-human primate model of depression. Braz. J. Psychiatry 41, 280-288. doi: 10.1590/1516-4446-2018-0140

Dalla, C., Pitychoutis, P. M., Kokras, N., and Papadopoulou-Daifoti, Z. (2010). Sex differences in animal models of depression and antidepressant response. Basic Clin. Pharmacol. Toxicol. 106, 226-233. doi: 10.1111/j.1742-7843.2009. 00516.x

de Almeida, R. N., de Galvão, A. C. M., da Silva, F. S., dos Silva, E. A. S., PalhanoFontes, F., Maia-de-Oliveira, J. P., et al. (2019). Modulation of serum brainderived neurotrophic factor by a single dose of ayahuasca: observation from a randomized controlled trial. Front. Psychol. 10:1234. doi: 10.3389/fpsyg.2019. 01234

de Castro Leão, A., Duarte Dória Neto, A., and de Sousa, M. B. C. (2009). New developmental stages for common marmosets (Callithrix jacchus) using mass and age variables obtained by K-means algorithm and self-organizing maps (SOM). Comput. Biol. Med. 39, 853-859. doi: 10.1016/j.compbiomed.2009.05. 009

de Menezes Galvão, A. C., Ferreira, R. G., de Sousa, M. B. C., and GalvãoCoelho, N. L. (2016). Physiological and behavioral responses to routine procedures in captive common marmosets (Callithrix jacchus). Primates 57, 421-431. doi: 10.1007/s10329-016-0526-2

de Sousa, M. B. C. (2017). "Endocrinological studies in non-human primates: significant contribution for conservation and experimental biology," in A Primatologia no Brasil, Vol. 14, eds Valdir Luna da Silva, Renata Gonçalves Ferreira and Maria Adélia Borstelmann de 
Oliveira (Recife, Brazil: Sociedade Brasileira de Primatologia), 311-334. Available online at: https://www.sbprimatologia.org.br/wpcontent/uploads/2021/03/Primatologia-14-Completo.pdf.

de Sousa, M. B. C., de Galvão, A. C. M., Sales, C. J. R., de Castro, D. C., and GalvãoCoelho, N. L. (2015). Endocrine and cognitive adaptations to cope with stress in immature common marmosets (Callithrix jacchus): sex and age matter. Front. Psychiatry 6:160. doi: 10.3389/fpsyt.2015.00160

de Sousa, M. B. C., Pontes, M. C., Galvão, A. C. M., Silva, H. P. A., and Galvão-Coelho, N. L. (2019). Social interactions androgens levels in marmosets (Callithrix jacchus) in field and laboratory studies: a preliminary investigation of the Challenge Hypothesis. Gen. Comp. Endocrinol. 273, 192-201. doi: 10.1016/j.ygcen.2018.07.016

de Sousa, M. B. C., and Ziegler, T. E. (1998). Diurnal variation on the excretion patterns of fecal steroids in common marmoset (Callithrix jacchus) females. Am. J. Primatol. 46, 105-117. doi: 10.1002/(SICI)10982345(1998)46:2<105::AID-AJP1 >3.0.CO;2-\#

Dean, J., and Keshavan, M. (2017). The neurobiology of depression: an integrated view. Asian J. Psychiatr. 27, 101-111. doi: 10.1016/j.ajp.2017.01.025

Dettling, A. C., Feldon, J., and Pryce, C. R. (2002a). Early deprivation and behavioral and physiological responses to social separation/novelty in the marmoset. Pharmacol. Biochem. Behav. 73, 259-269. doi: 10.1016/s00913057(02)00785-2

Dettling, A. C., Feldon, J., and Pryce, C. R. (2002b). Repeated parental deprivation in the infant common marmoset (Callithrix jacchus, primates) and analysis of its effects on early development. Biol. Psychiatry 52, 1037-1046. doi: 10.1016/s0006-3223(02)01460-9

Dettling, A. C., Schnell, C. R., Maier, C., Feldon, J., and Pryce, C. R. (2007). Behavioral and physiological effects of an infant-neglect manipulation in a bi-parental, twinning primate: impact is dependent on familial factors. Psychoneuroendocrinology 32, 331-349. doi: 10.1016/j.psyneuen.2007. 01.005

Dieleman, G. C., Huizink, A. C., Tulen, J. H. M., Utens, E. M. W. J., Creemers, H. E., van der Ende, J., et al. (2015). Alterations in HPA-axis and autonomic nervous system functioning in childhood anxiety disorders point to a chronic stress hypothesis. Psychoneuroendocrinology 51, 135-150. doi: 10.1016/j.psyneuen.2014.09.002

Digby, L. J. (1995). Social organization in a wild population of Callithrix jacchus: II. Intragroup social behavior. Primates 36, 361-375. doi: 10.1007/bf02382859

Digby, L. J. (1999). Sexual behavior and extragroup copulations in a wild population of common marmosets (Callithrix jacchus). Folia Primatol. 70, 136-145. doi: 10.1159/000021686

Digby, L. J., and Barreto, C. E. (1993). Social organization in a wild population of Callithrix jacchus. Folia Primatol. 61, 123-134. doi: 10.1159/0001 56739

Elfeddali, I., van der Feltz-Cornelis, C., van Os, J., Knappe, S., Vieta, E., Wittchen, H.-U., et al. (2014). Horizon 2020 priorities in clinical mental health research: results of a consensus-based ROAMER expert survey. Int. J. Environ. Res. Public Health 11, 10915-10939. doi: 10.3390/ijerph111 010915

Epple, G. (1970). Maintenance breeding, and development of marmoset monkeys (Callithricidae) in captivity. Folia Primatol. 12, 56-76. doi: 10.1159/0001 55281

Evans, S., and Poole, T. B. (1983). Pair-bond formation and breeding success in the common marmoset Callithrix jacchus jacchus. Int. J. Primatol. 4, 83-97. doi: $10.1007 / \mathrm{bf} 02739361$

Faulkes, C. G., Arruda, M. F., and Cruz, M. A. O. M. (2009). "Genetic structure within and among populations of the common marmoset, Callithrix jacchus: implications for cooperative breeding," in The Smallest Anthropoids: The Marmoset/Callimico Radiation, eds S. M. Ford, L. M. Porter and L. C. Davis (Boston, MA: Springer US). doi: 10.1007/978-1-4419-0293-1_5

Ferreira Raminelli, J. L., Cordeiro de Sousa, M. B. C., Sousa Cunha, M., and Veloso Barbosa, M. F. (2001). Morning and afternoon patterns of fecal cortisol excretion among reproductive and non-reproductive male and female common marmosets, Callithrix jacchus. Biol. Rhythm Res. 32, 159-167. doi: 10.1076/brhm.32.2.159.1357

Galvão-Coelho, N. L., de Menezes Galvão, A. C., de Almeida, R. N., Palhano-Fontes, F., Campos Braga, I., Lobão Soares, B., et al. (2020). Changes in inflammatory biomarkers are related to the antidepressant effects of Ayahuasca. J. Psychopharmacol. 34, 1125-1133. doi: 10.1177/ 0269881120936486

Galvão-Coelho, N. L., Galvão, A. C. D M., Silva, F. S. D., and de Sousa, M. B. C. (2017). Common marmosets: a potential translational animal model of juvenile depression. Front. Psychiatry 8:175. doi: 10.1016/j.chemosphere.2020. 129190

Galvão-Coelho, N. L., Marx, W., Gonzalez, M., Sinclair, J., de Manincor, M., Perkins, D., et al. (2021). Classic serotonergic psychedelics for mood and depressive symptoms: a meta-analysis of mood disorder patients and healthy participants. Psychopharmacology 238, 341-354. doi: 10.1007/s00213-02005719-1

Galvão-Coelho, N. L., Silva, H. P. A., and de Sousa, M. B. C. (2012). The influence of sex and relatedness on stress response in common marmosets (Callithrix jacchus). Am. J. Primatol. 74, 819-827. doi: 10.1002/ajp.22032

Galvão-Coelho, N. L., Silva, H. P. A., Leäo, A. C., and de Sousa, M. B. C. (2008). Common marmosets (Callithrix jacchus) as a potential animal model for studying psychological disorders associated with high and low responsiveness of the hypothalamic-pituitary-ad renal axis. Rev. Neurosci. 19, 187-201. doi: 10.1515/revneuro.2008.19.2-3.187

Garber, P. A., McKenney, A., Bartling-John, E., Bicca-Marques, J. C., De la Fuente, M. F., Abreu, F., et al. (2020). Life in a harsh environment: the effects of age, sex, reproductive condition, and season on hair cortisol concentration in a wild non-human primate. PeerJ 8:e9365. doi: 10.7717/peerj.9365

Haro, J. M., Ayuso-Mateos, J. L., Bitter, I., Demotes-Mainard, J., Leboyer, M., Lewis, S. W., et al. (2014). ROAMER: roadmap for mental health research in Europe. Int. J. Methods Psychiatr. Res. 23, 1-14. doi: 10.1002/mpr.1406

Hennessy, M. B., Kaiser, S., and Sachser, N. (2009). Social buffering of the stress response: diversity, mechanisms, and functions. Front. Neuroendocrinol. 30, 470-482. doi: 10.1016/j.yfrne.2009.06.001

Hennessy, M. B., McCowan, B., Jiang, J., and Capitanio, J. P. (2014). Depressivelike behavioral response of adult male rhesus monkeys during routine animal husbandry procedure. Front. Behav. Neurosci. 8:309. doi: 10.3389/fnbeh.2014. 00309

Herman, J. P., McKlveen, J. M., Ghosal, S., Kopp, B., Wulsin, A., Makinson, R., et al. (2016). Regulation of the hypothalamic-pituitary-adrenocortical stress response. Compr. Physiol. 6, 603-621. doi: 10.1002/cphy.c150015

Hollander, J. A., Cory-Slechta, D. A., Jacka, F. N., Szabo, S. T., Guilarte, T. R., Bilbo, S. D., et al. (2020). Beyond the looking glass: recent advances in understanding the impact of environmental exposures on neuropsychiatric disease. Neuropsychopharmacology 45, 1086-1096. doi: 10.1038/s41386-0200648-5

Ingram, J. C. (1977). Interactions between parents and infants and the development of independence in the common marmoset (Callithrix jacchus). Anim. Behav. 25, 811-827. doi: 10.1016/0003-3472(77)90035-5

Insel, T., Cuthbert, B., Garvey, M., Heinssen, R., Pine, D. S., Quinn, K., et al. (2010). Research domain criteria (RDoC): toward a new classification framework for research on mental disorders. Am. J. Psychiatry 167, 748-751. doi: 10.1176/appi.ajp.2010.09091379

Johnson, E. O., Kamilaris, T. C., Carter, C. S., Calogero, A. E., Gold, P. W., and Chrousos, G. P. (1996). The biobehavioral consequences of psychogenic stress in a small, social primate (Callithrix jacchus jacchus). Biol. Psychiatry 40, 317-337. doi: 10.1016/0006-3223(95)00397-5

Juhasz, G., Dunham, J. S., McKie, S., Thomas, E., Downey, D., Chase, D., et al. (2011). The CREB1-BDNF-NTRK2 pathway in depression: multiple gene-cognition-environment interactions. Biol. Psychiatry 69, 762-771. doi: 10.1016/j.biopsych.2010.11.019

Juruena, M. F., Eror, F., Cleare, A. J., and Young, A. H. (2020). The role of early life stress in HPA axis and anxiety. Adv. Exp. Med. Biol. 1191, 141-153. doi: 10.1007/978-981-32-9705-0_9

Kappeler, P. M. (2019). A framework for studying social complexity. Behav. Ecol. Sociobiol. 73:13. doi: 10.1007/s00265-018-2601-8

Keller, J., Flores, B., Gomez, R. G., Solvason, H. B., Kenna, H., Williams, G. H., et al. (2006). Cortisol circadian rhythm alterations in psychotic major depression. Biol. Psychiatry 60, 275-281. doi: 10.1016/j.biopsych.2005.10.014

Knowles, G., Gayer-Anderson, C., Beards, S., Blakey, R., Davis, S., Lowis, K., et al. (2021). Mental distress among young people in inner cities: the Resilience, Ethnicity and AdolesCent Mental Health (REACH) study. J. Epidemiol. Commun. Health 75, 515-522. doi: 10.1136/jech-2020-214315 
Kokras, N., and Dalla, C. (2014). Sex differences in animal models of psychiatric disorders. Br. J. Pharmacol. 171, 4595-4619. doi: 10.1111/bph.12710

Kompagne, H., Bárdos, G., Szénási, G., Gacsályi, I., Hársing, L. G., and Lévay, G. (2008). Chronic mild stress generates clear depressive but ambiguous anxiety-like behaviour in rats. Behav. Brain Res. 193, 311-314. doi: 10.1016/j. bbr.2008.06.008

Lazaro-Perea, C. (2001). Intergroup interactions in wild common marmosets, Callithrix jacchus: territorial defence and assessment of neighbours. Anim. Behav. 62, 11-21. doi: 10.1006/anbe.2000.1726

Li, X., Xu, F., Xie, L., Ji, Y., Cheng, K., Zhou, Q., et al. (2013). Depressionlike behavioral phenotypes by social and social plus visual isolation in the adult female macaca fascicularis. PLoS One 8:e73293. doi: 10.1371/journal. pone. 0073293

Martinez, F. O., Sica, A., Mantovani, A., and Locati, M. (2008). Macrophage activation and polarization. Front. Biosci. 13, 453-461. doi: 10.2741/2692

Missler, M., Wolff, J. R., Rothe, H., Heger, W., Merker, H., Treiber, A., et al. (1992). Developmental biology of the common marmoset: proposal for a "postnatal staging". J. Med. Primatol. 21, 285-298. doi: 10.1111/j.1600-0684.1992.tb 00593.x

Nogueira, V. B., Imparato, D. O., de Souza, S. J., and de Sousa, M. B. C. (2018). Sex-biased gene expression in the frontal cortex of common marmosets (Callithrix jacchus) and potential behavioral correlates. Brain Behav. 8:e01148. doi: $10.1002 / b r b 3.1148$

Okano, H., and Mitra, P. (2015). Brain-mapping projects using the common marmoset. Neurosci. Res. 93, 3-7. doi: 10.1016/j.neures.2014.08.014

Okano, H., Miyawaki, A., and Kasai, K. (2015). Brain/MINDS: brainmapping project in Japan. Philos. Trans. R. Soc. B Biol. Sci. 370:20140310. doi: $10.1098 /$ rstb.2014.0310

Øverli, Ø., Korzan, W. J., Höglund, E., Winberg, S., Bollig, H., Watt, M., et al. (2004). Stress coping style predicts aggression and social dominance in rainbow trout. Horm. Behav. 45, 235-241. doi: 10.1016/j.yhbeh.2003. 12.002

Palhano-Fontes, F., Alchieri, J. C., Oliveira, J. P. M., Soares, B. L., Hallak, J. E. C., Galvao-Coelho, N., et al. (2014). "The therapeutic potentials of ayahuasca in the treatment of depression," in The Therapeutic Use of Ayahuasca, eds B. Labate and C. Cavnar (Berlin, Heidelberg: Springer Berlin Heidelberg), 23-39.

Palhano-Fontes, F., Barreto, D., Onias, H., Andrade, K. C., Novaes, M. M., Pessoa, J. A., et al. (2019). Rapid antidepressant effects of the psychedelic ayahuasca in treatment-resistant depression: a randomized placebocontrolled trial. Psychol. Med. 49, 655-663. doi: 10.1017/S00332917180 01356

Palhano-Fontes, F., Mota-Rolim, S, Lobão-Soares, B., Galvão-Coelho, N., MaiaOliveira, J. P., and Araújo, D. B. (2021). "Recent evidence on the antidepressant effects of Ayahuasca," in Ayahuasca Healing and Science, eds B. C. Labate and C. Cavnar (Cham: Springer), 22-41. doi: 10.1177/0004867421 998785

Perkins, D., Sarris, J., Rossell, S., Bonomo, Y., Forbes, D., Davey, C., et al. (2021). Medicinal psychedelics for mental health and addiction: advancing research of an emerging paradigm. Aust. NZ J. Psychiatry doi: 10.1177/0004867421998785. [Epub ahead of print].

Phillips, K. A., Tukan, A. N., Rigodanzo, A. D., Reusch, R. T., Brasky, K. M., and Meyer, J. S. (2018). Quantification of hair cortisol concentration in common marmosets (Callithrix jacchus) and tufted capuchins (Cebus apella). Am. J. Primatol. 80:e22879. doi: 10.1002/ajp.22879

Pryce, C. R., Aubert, Y., Maier, C., Pearce, P. C., and Fuchs, E. (2011). The developmental impact of prenatal stress, prenatal dexamethasone and postnatal social stress on physiology, behaviour and neuroanatomy of primate offspring: studies in rhesus macaque and common marmoset. Psychopharmacology 214, 33-53. doi: 10.1007/s00213-010-1989-2

Pryce, C. R., Dettling, A. C., Spengler, M., Schnell, C. R., and Feldon, J. (2004a). Deprivation of parenting disrupts development of homeostatic and reward systems in marmoset monkey offspring. Biol. Psychiatry 56, 72-79. doi: 10.1016/j.biopsych.2004.05.002

Pryce, C. R., Dettling, A. C., Spengler, M., Spaete, C., and Feldon, J. (2004b). Evidence for altered monoamine activity and emotional and cognitive disturbance in marmoset monkeys exposed to early life stress. Ann. N Y Acad. Sci. 1032, 245-249. doi: 10.1196/annals. 1314.030
Roberts, M. L., Buchanan, K. L., Hasselquist, D., and Evans, M. R. (2007). Effects of testosterone and corticosterone on immunocompetence in the zebra finch. Horm. Behav. 51, 126-134. doi: 10.1016/j.yhbeh.2006.09.004

Salgado, J. V., and Sandner, G. (2013). A critical overview of animal models of psychiatric disorders: challenges and perspectives. Braz. J. Psychiatry 35, S77-S81. doi: 10.1590/1516-4446-2013-1156

Santiago, G. T. P., de Menezes Galvão, A. C., de Almeida, R. N., Mota-Rolim, S. A., Palhano-Fontes, F., Maia-de-Oliveira, J. P., et al. (2020). Changes in cortisol but not in brain-derived neurotrophic factor modulate the association between sleep disturbances and major depression. Front. Behav. Neurosci. 14:44. doi: 10.3389/fnbeh.2020.00044

Sarris, J., Perkins, D., Cribb, L., Schubert, V., Opaleye, E., Bouso, J. C., et al. (2021). Ayahuasca use and reported effects on depression and anxiety symptoms: an international cross-sectional study of 11,912 Consumers. J. Affect. Disord. Rep. 4:100098. doi: 10.1016/j.jadr.2021.100098

Sasaki, E. (2015). Prospects for genetically modified non-human primate models, including the common marmoset. Neurosci. Res. 93, 110-115. doi: 10.1016/j. neures.2015.01.011

Sasaki, E., Suemizu, H., Shimada, A., Hanazawa, K., Oiwa, R., Kamioka, M., et al. (2009). Generation of transgenic non-human primates with germline transmission. Nature 459, 523-527. doi: 10.1038/nature08090

Schiel, N., and Souto, A. (2017). The common marmoset: an overview of its natural history, ecology and behavior. Dev. Neurobiol. 77, 244-262. doi: 10.1002/dneu.22458

Schjolden, J., Backström, T., Pulman, K., Pottinger, T., and Winberg, S. (2005). Divergence in behavioural responses to stress in two strains of rainbow trout (Oncorhynchus mykiss) with contrasting stress responsiveness. Horm. Behav. 48, 537-544. doi: 10.1016/j.yhbeh.2005.04.008

Schultz-Darken, N., Braun, K. M., and Emborg, M. E. (2016). Neurobehavioral development of common marmoset monkeys. Dev. Psychobiol. 58, 141-158. doi: $10.1002 / \operatorname{dev} .21360$

Sgoifo, A., Koolhaas, J., De Boer, S., Musso, E., Stilli, D., Buwalda, B., et al. (1999). Social stress, autonomic neural activation, and cardiac activity in rats. Neurosci. Biobehav. Rev. 23, 915-923. doi: 10.1016/s0149-7634(99) 00025-1

Stackpole, C. A., Clarke, I. J., Breen, K. M., Turner, A. I., Karsch, F. J., and Tilbrook, A. J. (2006). Sex difference in the suppressive effect of cortisol on pulsatile secretion of luteinizing hormone in sheep. Endocrinology 147, 5921-5931. doi: 10.1210/en.2006-0667

Stevenson, M. F., and Poole, T. B. (1976). An ethogram of the common marmoset (Calithrix jacchus jacchus): general behavioural repertoire. Anim. Behav. 24, 428-451. doi: 10.1016/s0003-3472(76)80053-x

Stevenson, M. F., and Rylands, A. B. (1988). "The marmosets, genus Callithrix," in Ecology and Behavior of Neotropical Primates, eds R. A. Mittermeier, A. B. Rylands, A. Coimbra-Filho and G. A. B. Fonseca (Washington, DC: World Wildlife Fund), 131-222.

Tafet, G. E., and Bernardini, R. (2003). Psychoneuroendocrinological links between chronic stress and depression. Prog. Neuropsychopharmacol. Biol. Psychiatry 27, 893-903. doi: 10.1016/S0278-5846(03)00162-3

Tardif, S. D., Smucny, D. A., Abbott, D. H., Mansfield, K., Schultz-Darken, N., and Yamamoto, M. E. (2003). Reproduction in captive common marmosets (Callithrix jacchus). Comp. Med. 53, 364-368.

Teng, T., Shively, C. A., Li, X., Jiang, X., Neigh, G. N., Yin, B., et al. (2021). Chronic unpredictable mild stress produces depressive-like behavior, hypercortisolemia, and metabolic dysfunction in adolescent cynomolgus monkeys. Transl. Psychiatry 11:9. doi: 10.1038/s41398-02001132-6

Thalén, B.-E., Mørkrid, L., Kjellman, B. F., and Wetterberg, L. (1997). Cortisol in light treatment of seasonal and non-seasonal depression: relationship between melatonin and Cortisol. Acta Psychiatr. Scand. 96, 385-394. doi: 10.1111/j. 1600-0447.1997.tb09934.x

Thapar, A., Collishaw, S., Pine, D. S., and Thapar, A. K. (2012). Depression in adolescence. Lancet 379, 1056-1067. doi: 10.1016/S0140-6736(11) 60871-4

van der Staay, F. J., de Groot, J., Schuurman, T., and Korte, S. M. (2008). Repeated social defeat in female pigs does not induce neuroendocrine symptoms of depression, but behavioral adaptation. Physiol. Behav. 93, 453-460. doi: 10.1016/j.physbeh.2007.10.002 
Veenema, A. H., Meijer, O. C., de Kloet, E. R., Koolhaas, J. M., and Bohus, B. G. (2003). Differences in basal and stress-induced HPA regulation of wild house mice selected for high and low aggression. Horm. Behav. 43, 197-204. doi: 10.1016/s0018-506x(02)00013-2

Woodcock, A. (1983). The social relationships of twin common marmosets (Callithrix jacchus) and their breeding success. Primates 24, 501-514. doi: $10.1007 / \mathrm{bf} 02381683$

Yamamoto, M. E. (1993). "From dependence to sexual maturity: the behavioural ontogeny of Callitrichidae," in Marmosets and Tamarins: Systematics Behaviour and Ecology, ed A. B. Rylands (London: Oxford University Press), 235-254.

Yamamoto, M. E., Araújo, A., de Sousa, M. B. C., and Arruda, M. D. F. (2010). "Social organization in Callithrix jacchus," in Advances in the Study of Behavior, Vol. 42, ed R. H. F. Macedo (New York: Academic Press), 42, 259-273.

Yasue, M., Nakagami, A., Banno, T., Nakagaki, K., Ichinohe, N., and Kawai, N. (2015). Indifference of marmosets with prenatal valproate exposure to third-partynon-reciprocal interactions with otherwise avoided non-reciprocal individuals. Behav. Brain Res. 292, 323-326. doi: 10.1016/j.bbr.2015. 06.006

Yehuda, R., Hoge, C. W., McFarlane, A. C., Vermetten, E., Lanius, R. A., Nievergelt, C. M., et al. (2015). Post-traumatic stress disorder. Nat. Rev. Dis. Primers 1:15057. doi: 10.1038/nrdp.2015.57

Conflict of Interest: The authors declare that the research was conducted in the absence of any commercial or financial relationships that could be construed as a potential conflict of interest.

Copyright (c) 2021 de Sousa, de Meiroz Grilo and Galvão-Coelho. This is an open-access article distributed under the terms of the Creative Commons Attribution License (CC BY). The use, distribution or reproduction in other forums is permitted, provided the original author(s) and the copyright owner(s) are credited and that the original publication in this journal is cited, in accordance with accepted academic practice. No use, distribution or reproduction is permitted which does not comply with these terms. 